\title{
First Observations of Energy Budget and Bulk Fluxes at Ny Ålesund (Svalbard) during a 2010 Transition Period as Analyzed with the BEAR Station
}

\author{
Alain Weill, ${ }^{1}$ Laurence Eymard, ${ }^{2}$ Frédéric Vivier, ${ }^{2}$ Ania Matulka, ${ }^{1}$ Rodrigue Loisil, ${ }^{3}$ \\ Nadir Amarouche, ${ }^{3}$ Jean Michel Panel, ${ }^{4}$ Antonio Lourenço, ${ }^{2}$ Angelo Viola, ${ }^{5}$ Vito Vitale, \\ Stefania Argentini, ${ }^{5}$ and Heike Kupfer ${ }^{6}$ \\ ${ }^{1}$ LATMOS (ESTER), 11 Boulevard D'Alembert, 78280 Guyancourt, France \\ ${ }^{2}$ LOCEAN, Université Pierre et Marie Curie, Tour 45, 4 Place Jussieu, 75005 Paris, France \\ ${ }^{3}$ DT INSU, 4 place Aristide Briand, 92195 Meudon Cedex, France \\ ${ }^{4}$ Centre d'Etude de la Neige (Meteo France), 1441 rue de la Piscine, Grenoble Cedex 9, France \\ ${ }^{5}$ Istituto di Scienze dell'Atmosfera e del Clima (ISAC), Consiglio Nazionale delle Ricerche (CNR), Via Fosso del Cavaliere, \\ 10000133 Rome, Italy \\ ${ }^{6}$ Institute of Building Climatology, Faculty of Architecture TU Dresden, Zellescher Weg 17, 01062 Dresden, Germany
}

Correspondence should be addressed to Alain Weill, alain.weill@latmos.ipsl.fr

Received 30 January 2012; Accepted 13 March 2012

Academic Editors: D. Moreira and A. Saha

Copyright (C) 2012 Alain Weill et al. This is an open access article distributed under the Creative Commons Attribution License, which permits unrestricted use, distribution, and reproduction in any medium, provided the original work is properly cited.

\begin{abstract}
A small-size meteorological mast, BEAR (Budget of Energy for Arctic regions) has been developed as a part of a new autonomous buoy for monitoring the sea ice mass balance. BEAR complements observations of the thickness and thermodynamic properties of the ice/snow pack determined by the so-called Ice-T (Ice-Thickness) buoy, giving access to bulk fluxes and energy budget at the surface, using meteorological measurements. The BEAR mast has been tested with success during ten days in April-May 2010 at Ny Alesund, in the Svalbard archipelago (Norway) showing that meteorological data were close to measurements at the same level of the Italian Climate Change Tower (CCT) from the ISAC-CNR. A discussion is undertaken on bulk fluxes determination and uncertainties. Particularly, the strategy to systematically use different relevant fluxes parameterizations is pointed out to explore flux range uncertainty before to analyze energy budget. Net radiation, bulk fluxes and energy budget are estimated using as average 10 minutes, 24 hours and the ten days of the experiment. The observation period was very short, but we observe a spring transition when the net radiation begins to warm the surface while the very small turbulent heat flux cools the surface.
\end{abstract}

\section{Introduction}

The most conspicuous manifestations of the ongoing climate warming are found in the Arctic, where the multiyear ice decline is larger than expected from climatic scenarios (IPCC Fourth Assessment Report: Climate Change 2007 (AR4)). There is a real need to better document heat and fresh water exchange processes at the ocean-ice-atmosphere interfaces to understand energy budget variability and to improve process parameterization in models.
Recent studies have been concerned by sea ice evolution as an integrative indicator of global warming, and different processes (atmospheric or oceanic) have been analyzed experimentally or using models: see, for example, to quote a few, Sedlar et al. [1] for the radiation impact on the surface, Hendricks et al. [2] for the sea ice-thickness climatic variability in the Svalbard region due to atmospheric wind forcing, and Timmermans et al. [3] concerning surface effects in the Arctic Ocean's Eurasian basin associated with a shift in the large scale circulation. All these studies either 
in the atmosphere, in the ocean, or at the ocean surface are very important to document the different processes which can contribute to the Arctic ice pack evolution since, as remarked by Rampal et al. [4], most recent climate models as IPCC climate models are not able to properly estimate ice thickness evolution. Documenting at the same time and the same location the ice pack properties and the atmospheric processes near the surface is therefore an important task to better understand the evolution of the ice-snow-atmosphere interface.

The OPTIMISM project (Observing dynamic and thermodynamic Processes involved in The sea Ice Mass balance from In Situ Measurement) is aimed at developing and deploying a small network of automated buoys system, built upon the "Ice-T" buoy prototype providing real-time measurement of sea-ice thickness and fluxes at the interfaces described in Vivier [5]. Studies will focus on a coastal polynya, a critical region for ice and dense water formation, as well as on the multiyear ice pack. The obtained data will also be relevant for the validation of the ESA (European Space Agency)'s Earth Explorer Cryosat-2 mission.

The "OPTIMISM" system consists of an ocean buoy to measure the physical properties of the sea and ice (currents, sea water temperature and salinity, sea ice thickness and temperature) and a meteorological mast upon it. The meteorological mast is the BEAR station concept (Budget of Energy for Arctic Region). For the OPTIMISM project, it has been tested during ten days in April-May 2010 at Ny Allesund (Spitsbergen), in the island of Svalbard archipelago in Norway, to assess its performance under polar conditions.

Spring in Arctic region at the Svalbard latitude corresponds to a transition regime in the radiation fluxes since solar visible radiation becomes more and more intense. If one considers, for example, general conclusions on the Arctic energy budget regimes, (see, e.g., Maykut [6], Barry et al. [7], Persson et al. [8]), it is obvious that close to April-May period, while latent heat fluxes are increasing and the sensible heat flux can reach positive values (cooling the surface), radiation fluxes become positive and warm the surface.

Figure 1 displays a schematic representation of the seasonal surface energy budget and the variations of its different components along the year. While the amplitude of the total turbulent heat flux can reach 10 to $20 \mathrm{Wm}^{-2}$ in MayJune and contributes to cool the surface, following [7], the net radiation flux amplitude can be more than $40 \mathrm{Wm}^{-2}$ warming the surface and largely contributing to the surface energy budget. SHEBA (Surface Heat Budget of the Arctic Ocean Experiment) observations, see [8], report smaller turbulent heat fluxes on the order of a few $\mathrm{Wm}^{-2}$ while net radiation exceeds $20 \mathrm{Wm}^{-2}$, altogether featuring indeed a surface warming.

In the next section, we describe the BEAR instrumentation and report first comparisons with other measurements close to the BEAR location around Ny Ålesund. Then, we present projected analysis methods to estimate energy budget and bulk fluxes. In the following section, we examine this first BEAR dataset, by analyzing heat fluxes, total net radiation and energy budget observations during this short period of April-May. The conclusion discusses the measurement

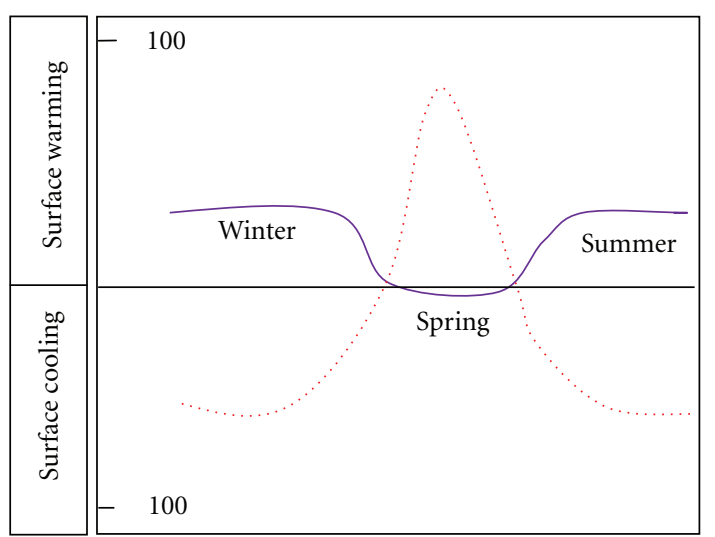

$$
\begin{aligned}
& \text { … Total net radiation } R_{n} \\
& \text { — Turbulent heat flux }(H+E)
\end{aligned}
$$

FIgURE 1: Sketch showing the evolution of the net radiation and turbulent fluxes along a year in Arctic regions. The ordinate is in arbitrary units to take into account a possible ratio between the different components. Typically, during SHEBA, maximum turbulent warming is close to $20 \mathrm{Wm}^{-2}$, and $50 \mathrm{Wm}^{-2}$ is the maximum infrared cooling during winter. Adopted from Maykut [6], Barry et al. [7], Persson et al. [8]. (Surface warming sign is often conventionally positive for oceanographers and negative for meteorologists).

strategy taking into account the precision relative to the chosen measurement method.

\section{BEAR Station Measurements}

2.1. System Description. The system has been designed to work in Arctic regions and uses available technology for cold environments.

(i) Wind speed and azimuth are obtained from a Young 05103-45 anemometer (instantaneous wind speed precision $\pm 0.3 \mathrm{~ms}^{-1}$ and azimuth precision $\pm 5.0 \mathrm{dg}$ ) designed for mountain and for polar regions. It is supposed to be less sensitive to frost than other wind measurement devices.

(ii) For shade temperature and relative humidity, HMP 155 from Vaïsala is used with a naturally ventilated shade. The temperature and humidity instantaneous precisions are $\pm 0.15^{\circ} \mathrm{C}$ and $\pm 2 \%$, respectively.

(iii) The four radiation components (global shortwave and infrared radiations) are obtained from a CNR4 system (with two upward and downward pyranometers and pyrgeometers) manufactured by Kipp and Zonen. The spectral range for shortwave radiation is between 300 and $2800 \mathrm{~nm}$ while infrared radiation is between $4500 \mathrm{~nm}$, and $42000 \mathrm{~nm}$. The expected accuracy for daily total net shortwave and net infrared net radiation is close to $10 \%$. A warming of the infrared pyrgeometer domes is performed to prevent from ice formation which demands substantial energy. 


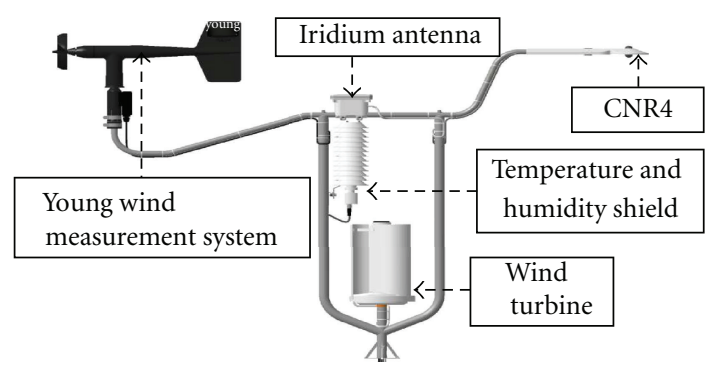

FIGURE 2: Conceptual scheme of the BEAR station.

A battery to be lodged in the buoy is dedicated to heating and is loaded with a Forgen 500 wind turbine whose rotation starts for a wind speed greater than about $5 \mathrm{~m} / \mathrm{s}$. The domes temperature is corrected for the infrared measurements.

The instrumentation is implemented on a $3 \mathrm{~kg}$ mast, and the whole system weight is lower than $9 \mathrm{~kg}$. During the Ny Ålesund validation experiment, the BEAR system was fixed on a gauge of the Ice-T buoy. Note that the BEAR station needs ancillary data such as surface temperature, ice and snow depth, snow temperature, atmospheric pressure, provided by Ice-T system in the final configuration. During the Ny-Ålesund experiment, however, additional sensors were deployed around the BEAR mast.

Figure 2 shows a scheme of the BEAR instrumentation and Figure 3 presents the experiment area: the system is located at about $70-80 \mathrm{~m}$ east of the meteorological mast ("Climate Change Tower," hereafter CCT) deployed by ISAC-CNR to limit slopes, shadow, and wake effects. GPS coordinates were $78^{\circ} 55^{\prime} 48^{\prime \prime}$ north and $11^{\circ} 52^{\prime} 12^{\prime \prime}$ east. These two systems are on a small hill NW of the Ny Ålesund village, in the vicinity of the airport (Figure 4).

This location was chosen by the ISAC-CNR team because it is well exposed to the dominant flow from north-east (along the main fjord orientation), with no building in the vicinity.

Around the site, mountains as high as $600 \mathrm{~m}$ are located west of the site (Figure 3). Finally, other meteorological and radiation measurements are performed close to the village, and comparisons could be performed with the AWI data (Kupfer et al. [9]) located SE of the village.

The BEAR system was installed from April 27 up to May 10,2010 , upon a snow cover. At this period, solar elevation is low and less than 17 degrees at 06:00 U.T. and 25 degrees between 09:00 and 13:00 U.T.

Orientation of the axis between CNR4 and Young has been optimized taking into account shadows effects of the different mountains. Figure 4 shows a view of the BEAR orientation. As the sun west position occurs close to 17:00 UT with an elevation of 15 degrees, the BEAR station is therefore not affected. Snow height variations were evaluated from a ruler fixed on the cylindrical mast supporting the BEAR system. Several measurements of snow temperature were performed, using sensors provided by Météo France (CEN): three sensors, respectively, at $3 \mathrm{~cm}, 7 \mathrm{~cm}$, and $12 \mathrm{~cm}$ depth, and four surface temperature probes fixed below a plate (2 of them) on a flat grid (diameter $20 \mathrm{~cm}$ ) to ensure measurements at $0-1.5 \mathrm{~cm}$ below the snow surface whatever the snow evolution is (snow fall or snow erosion).

\subsection{Comparisons between Meteorological and Radiative BEAR Data and Other Measurements over the Site (ISAC-CNR, AWI)}

2.2.1. BEAR Measurement Comparisons. Temperature, humidity, and wind data at $2 \mathrm{~m}$ level and radiation measurements at $32 \mathrm{~m}$ height from the ISAC-CNR tower were used for comparison with BEAR measurements. We also benefited from AWI data (meteorological and radiation measurements, at $2 \mathrm{~m}$ above the surface), see http://www.awi .de/infrastructure/stations/awipev_arctic_research_base/ co_operations/.

To distinguish the different stations, we hereafter note FR (FRench) for BEAR data, IT (ITalian) for ITalian tower data and G (German) for AWI data.

We compare here data at comparable levels for meteorological data, and we do not normalize these data at $10 \mathrm{~m}$ height because surface layers in these regions are often smaller than $10 \mathrm{~m}$ height. For radiation, we compare surface values using FR, IT, and, G, but, due to the $32 \mathrm{~m}$ height from IT radiation measurement, we expect some differences due to different footprints and attenuation.

Meteorological instruments used from IT are the same as BEAR instruments for wind temperature and humidity: a Young anemometer for the wind velocity and HMP45 probes for temperature and humidity. For the radiation measurement, IT tower used a CNR1 which is the old version of the CNR4 used for BEAR. For the G station, different instruments were used (a wind vane associated with a Thies system for the wind velocity, a PT100 for temperature, and a HMP 233 for humidity). The G radiation from AWI (Alfred Wegener Institute) is measured from different instruments: CM11 radiometers for shortwave upward and downward radiation and Eppley pyrgeometers for infrared radiation.

Table 1 gives a synoptic view of the comparisons between BEAR basic measurements with, respectively, $G$ and IT measurements. This can be considered as a first validation of the basic measurements of the BEAR station since it shows a better agreement for the measurements which were undertaken at the same location (IT).

At least for air temperature, wind speed and air humidity bias are small between FR and IT. For the G measurements, as $\mathrm{G}$ corresponds to a different location, the local characteristics are different since it is more characteristic of Ny Alesund "city effect" as can be observed on the wind rose in Figure 5.

Figure 5 indeed shows wind vector from the three stations and illustrates the different behavior: whatever the wind azimuth, smaller speeds are observed on the G site. 


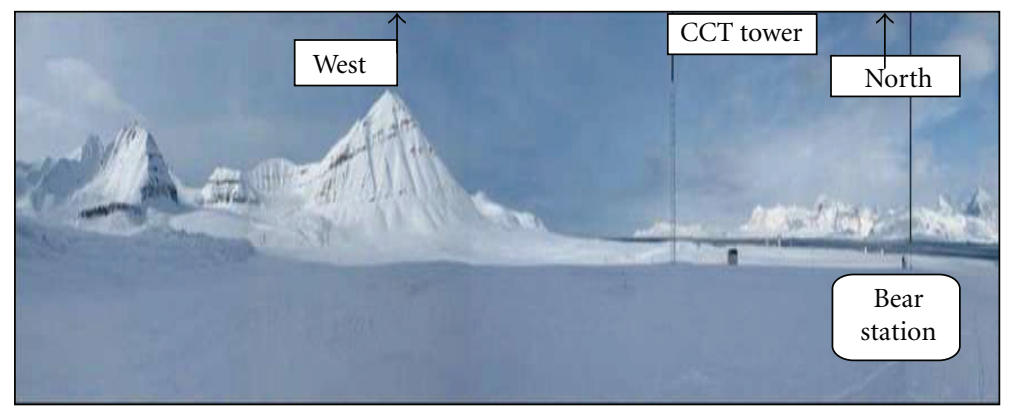

FIGURE 3: Panoramic photograph at 180 degrees of the site, showing the meteorological tower from Italian crew and the OPTIMISM BEAR mast.

TABLE 1: Regression of FR basic measurements between G and IT. Bias at the origin, slope and correlation are presented.

\begin{tabular}{lcccc}
\hline Parameter & $\begin{array}{c}\text { Regression } \\
\text { between FR } \\
\text { and G/IT }\end{array}$ & $\begin{array}{c}\text { Bias at the } \\
\text { origin }\end{array}$ & Slope & $\begin{array}{c}\text { Correlation } \\
\text { coefficient }\end{array}$ \\
\hline $\begin{array}{l}\text { Mean wind } \\
\text { intensity }(\mathrm{m} / \mathrm{s})\end{array}$ & $\mathrm{G}$ & 0.82 & 0.82 & 0.74 \\
Air temperature & IT & -0.19 & 1.03 & 0.99 \\
$\left({ }^{\circ} \mathrm{C}\right)$ & $\mathrm{G}$ & -0.13 & 1.00 & 0.98 \\
Relative humidity & IT & 0.36 & 0.99 & 1.00 \\
$(\%)$ & $\mathrm{G}$ & 19.2 & 0.77 & 0.86 \\
$\mathrm{Sw}_{\downarrow}\left(\mathrm{Wm}^{-2}\right)$ & $\mathrm{IT}$ & 5.8 & 0.98 & 1.00 \\
$\mathrm{Sw}_{\uparrow}\left(\mathrm{Wm}^{-2}\right)$ & $\mathrm{G}$ & -2.2 & 1.00 & 0.98 \\
& $\mathrm{IT}$ & 6 & 1.00 & 1.00 \\
& $\mathrm{G}$ & 10.9 & 0.96 & 0.98 \\
$\mathrm{Lw}_{\downarrow}\left(\mathrm{Wm}^{-2}\right)$ & $\mathrm{IT}$ & 12.8 & 1.03 & 0.99 \\
& $\mathrm{G}$ & -11.7 & 1.03 & 1.00 \\
$\mathrm{Lw}_{\uparrow}\left(\mathrm{Wm}^{-2}\right)$ & $\mathrm{IT}$ & -41.3 & 1.1 & 1.00 \\
& $\mathrm{G}$ & -33.4 & 1.09 & 0.98 \\
\hline
\end{tabular}

Although the wind roses are very similar for FR and IT, we notice a 10-degree difference which is probably due to a misorientation of BEAR. While FR and IT reach $11 \mathrm{~m} / \mathrm{s}$ close to 210 degrees azimuth sector, the maximum $G$ wind speed is close to $5 \mathrm{~m} / \mathrm{s}$. On average, the mean wind speed for $\mathrm{G}$ is $20 \%$ smaller than for FR and IT.

Regarding the radiation and especially long wave radiation, although the regression slope and correlation coefficients are very good, biases are high. Bias between FR and IT for long wave radiation can be partly explained by the difference of the measurement height ( $32 \mathrm{~m}$ for IT and $1.7 \mathrm{~m}$ for G) since IT measurements are not height corrected for upward and downward signal and there is also a different footprint due an imperfect cosine response. Moreover, instruments are different (a CNR1 is used for the tower), and, due to a long duration of use, radiation calibration of the tower can be also affected by some unknown drift.

Figure 6 shows a comparison between FR with IT and G total net radiation $\mathrm{Rn}$. We notice a better similarity between FR and IT, a larger scatter (more than a factor three), and notable differences between FR and G. If one analyzes regressions between FR and IT, the bias of $-13.8 \mathrm{Wm}^{-2}$ is associated with the difference between short wave radiations rather than with net long wave radiations. Maybe the linear relationship chosen to compare the instruments is too simple to explain the different instrumental behaviors and some meteorological effects as local clouds which can also explain some differences, but we do not have performed systematic cloudiness observations at each location.

A view of net radiation fluxes in Figure 7 shows the evolution of the diurnal cycle which is dominated by shortwave fluxes.

The drastic amplitude reduction as of May 4th corresponds to a period with more clouds during which net radiation becomes fully positive.

2.2.2. Surface Temperature. Estimation of surface temperature using SST (Snow Surface Temperature) inversion from infrared radiation is proposed by Claffey et al. [10] and Perovich et al. [11]:

$$
T_{s}=\left[\frac{\mathrm{Lw} \downarrow-((1.0-\varepsilon) \mathrm{Lw} \uparrow)}{(\varepsilon \sigma)}\right]^{1 / 4},
$$

where $\varepsilon$ is the surface emissivity, $\sigma$ the Stefan-Boltzmann constant, Lw $\downarrow$ the long-wave (infrared) incoming radiation and $\mathrm{Lw} \uparrow$ the transmitted long-wave radiation, both components being measured by the CNR4 systems. Reference [10] suggests that the emissivity upon ice or snow is equal to 0.99 , leading to an uncertainty on $T_{s}$ close to $0.5^{\circ} \mathrm{C}$.

This estimation is compared with the four temperatures probes at $1.5 \mathrm{~cm}$ below the snow surface $\mathrm{cm}$. Figure 8 shows the regressions between the four surface temperature probes named Surf1 to Surf4. The scatter is rather large, but bias at origin is smaller than $0.54^{\circ} \mathrm{C}$. We found that a 0.99 surface emissivity gives the best fit between surface temperature and radiation temperature. The same 0.99 surface emissivity was found to minimize the differences between surface and radiation temperatures from the IT tower.

The surface temperature can therefore be rather properly estimated using infrared radiation measurements. 


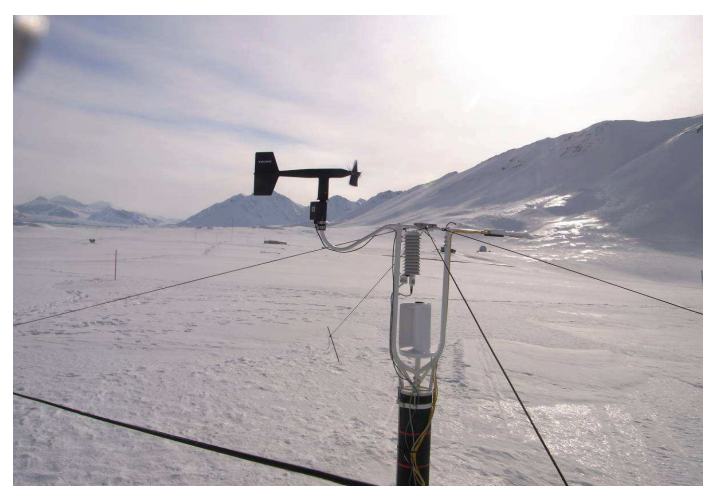

(a)

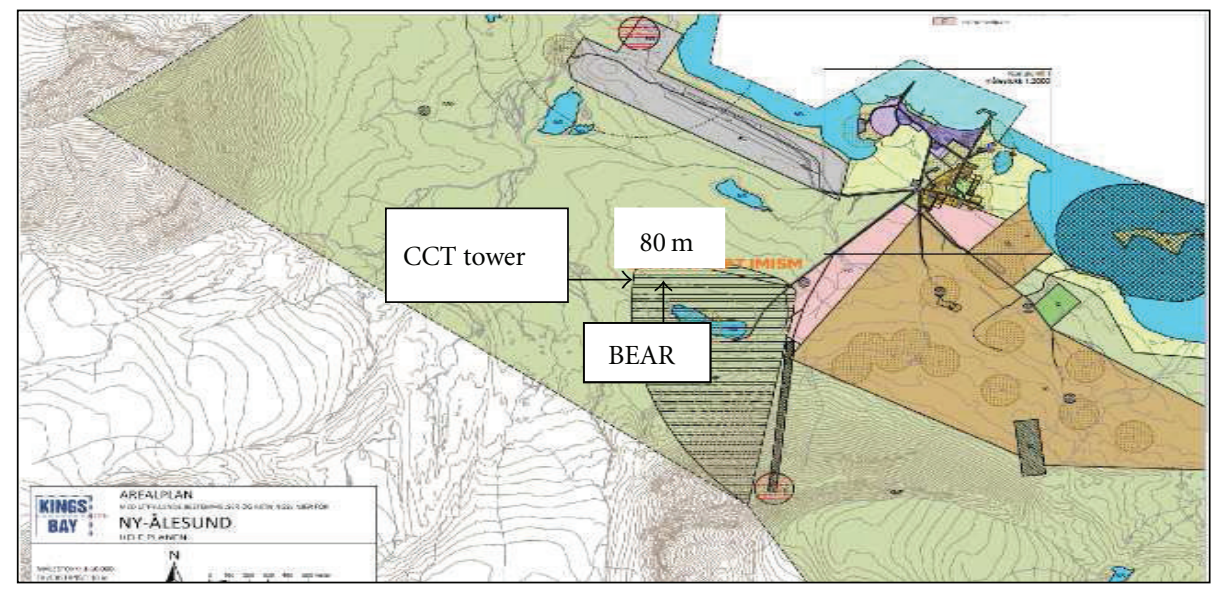

(b)

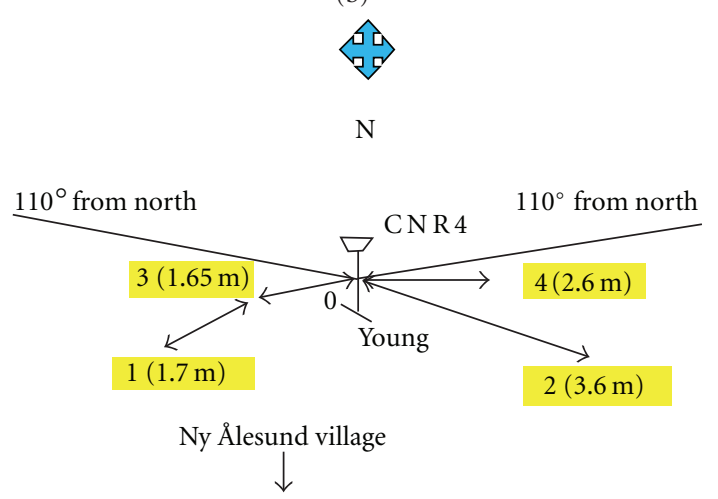

(c)

FIgure 4: Different views of the CCT and the BEAR sites. (a) Picture of the BEAR site. (b) Topography of the CCT site (with BEAR location). The different colored zones correspond to different types of topography. CCT tower and BEAR station are in the same relatively flat terrain which is hachured in the figure. (c) Sketch of the orientation of BEAR and surface temperature measurement (1 to 4) with distances indicated in metres.

\section{Surface Flux Analysis Method}

3.1. Energy Budget at the Surface. The energy budget at the surface can be expressed in a generic fashion, regardless of the surface type (snow, ice, water).

The total net radiation is

$$
R_{n}=(\mathrm{Sw} \downarrow-\mathrm{Sw} \uparrow)+(\mathrm{Lw} \downarrow-\mathrm{Lw} \uparrow),
$$

where $\mathrm{Sw}_{\mathrm{w}} \downarrow$ is the incoming shortwave radiation and $\mathrm{Sw} \uparrow$ the reflected shortwave radiation, both measured as well by the CNR4 system.
The net radiation is also

$$
R_{n}=H+E+\mathrm{TR},
$$

where $H$ is the turbulent sensible heat flux, $E$ is the latent heat flux, and TR is the residue of the budget and is the energy transmitted into the surface which can be either negative or positive following the amount of the different fluxes.

We take here the meteorological convention in which $H$ is negative if the sensible heat flux warms the surface and $E$ is always taken as positive. However, the latent heat flux can be 


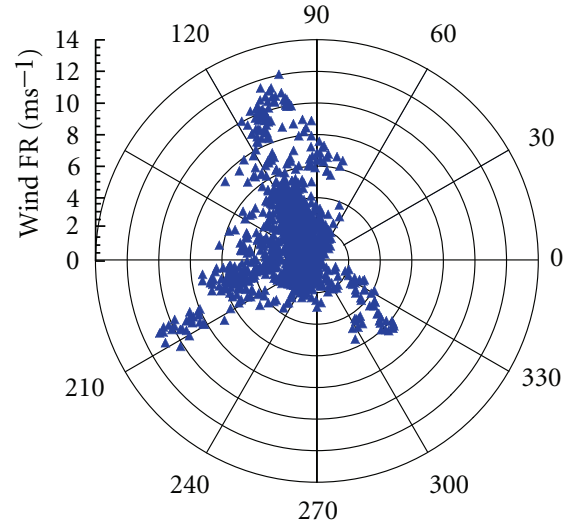

(a)

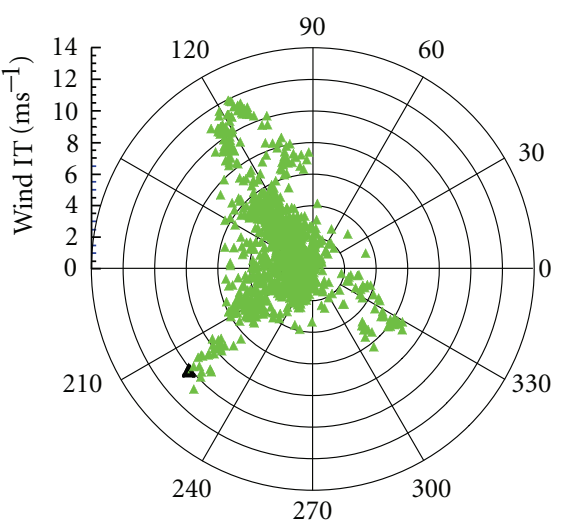

(b)

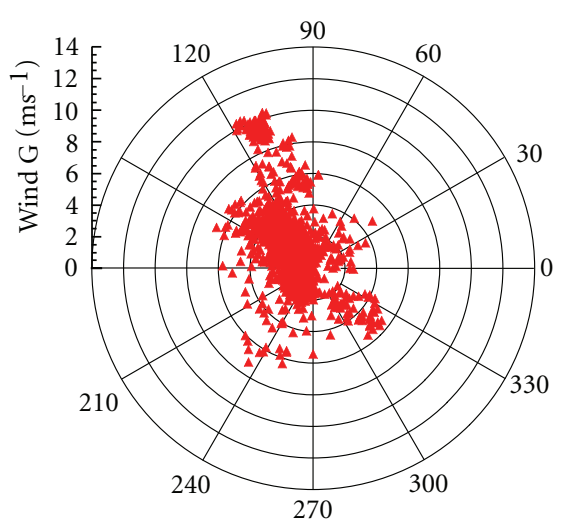

(c)

FIGURE 5: Windroses during the experiment from April 28 to May 8 (2010) for FR (in blue), IT (in green), and G (in red). We use conventional meteorological orientation ( 0 and 360 degrees for wind blowing from the north, 90 degrees for wind blowing from the east).

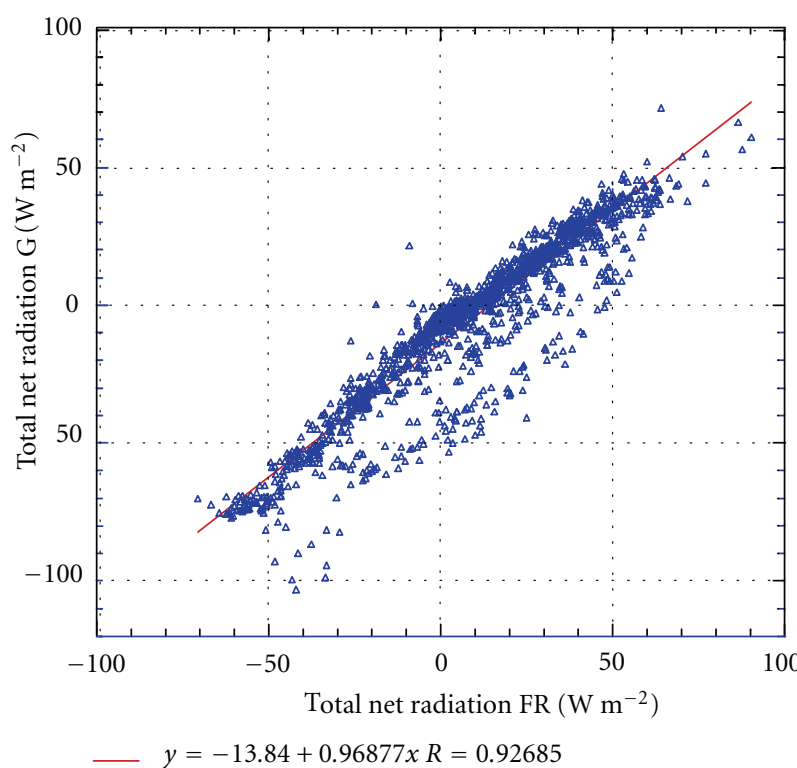

(a)

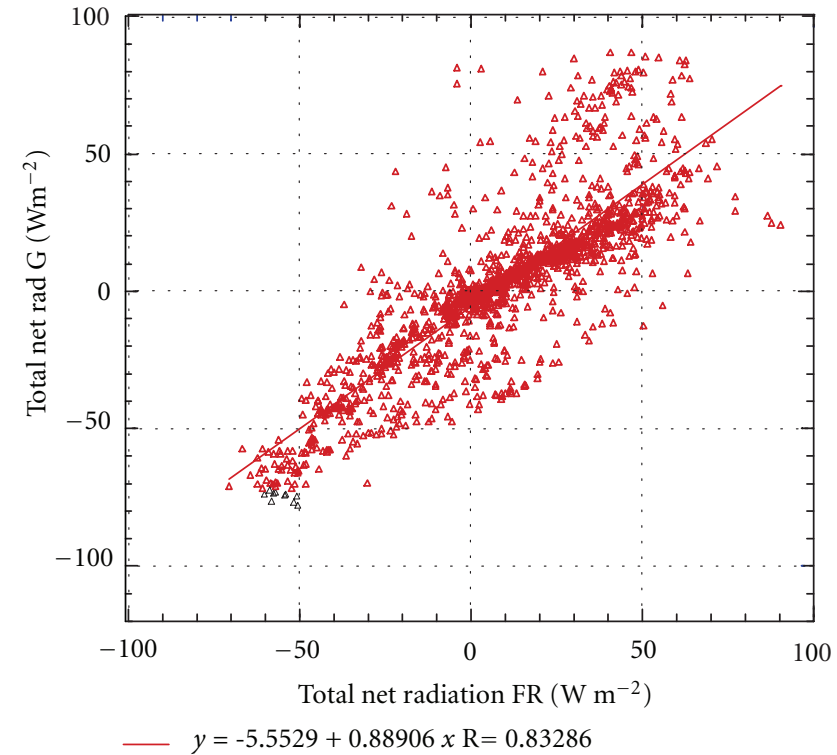

(b)

FIgure 6: Total net radiation scatter plot (FR and IT on the left, FR and G, on the right), from April 28 to May 9, 2010.

negative in case of surface condensation upon ice when an air mass supersaturated with respect to ice leads to water deposit on the surface, growing ice crystals (see Andreas et al. [12], Birch et al. [13]). These cases, which need new measurements or parameterizations, are not considered here but warrant to be studied. All the fluxes analyzed here correspond to cases without condensation, and $E$ is positive.

Usually, TR components which include conductive fluxes inside the snow and ice layer are expressed with respect to the ice/snow layer characteristics, but here we limit the budget presentation to what occurs at the surface. The energy transfer through the different layers will be estimated by the Ice-T instrument in the OPTIMISM project.
To compute the surface energy budget, it remains to estimate $H+E$, and, for that purpose, we have chosen to use bulk fluxes methods.

3.2. Bulk Fluxes in the Surface Layer with Constant Flux. We propose to use a simple method to estimate turbulent flux called bulk method. Such methods are usually used in neutral or unstable situations. However, in Arctic regions where the surface temperature (ice or snow) can be lower than the temperature of the lowest atmospheric layers, stably stratified layers are frequently observed and bulk methods must be adapted. Recently, Persson et al. [8] and Grachev et al. $([14,15])$ have proposed and validated bulk flux 


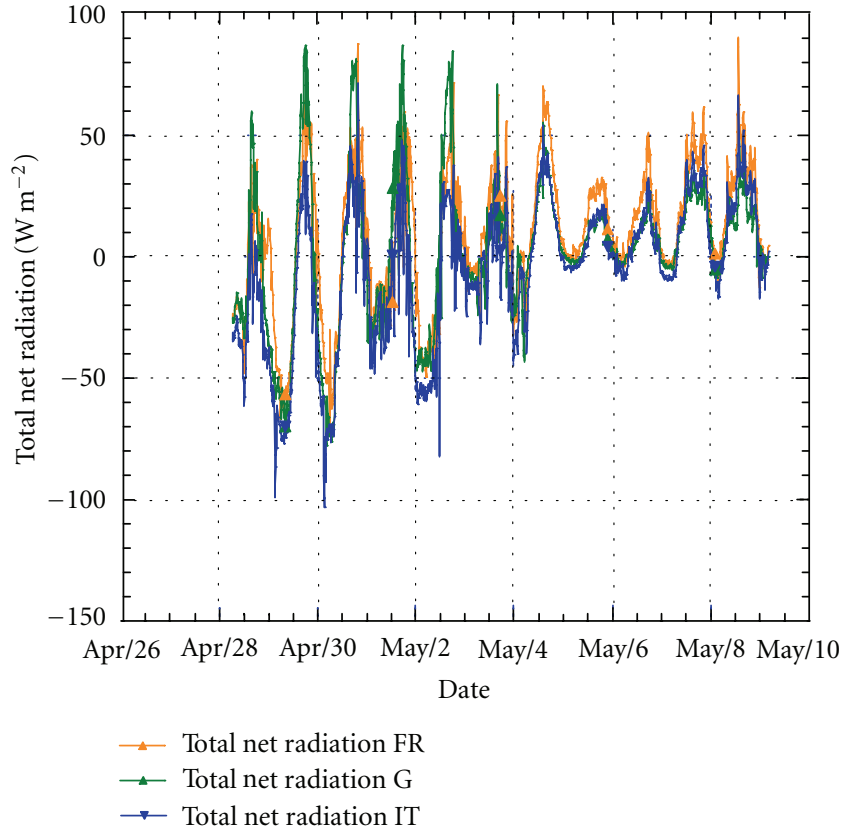

FIGURE 7: Evolution of net radiation during the experiment (FR, G and IT) from April 28 to May 9, 2010.

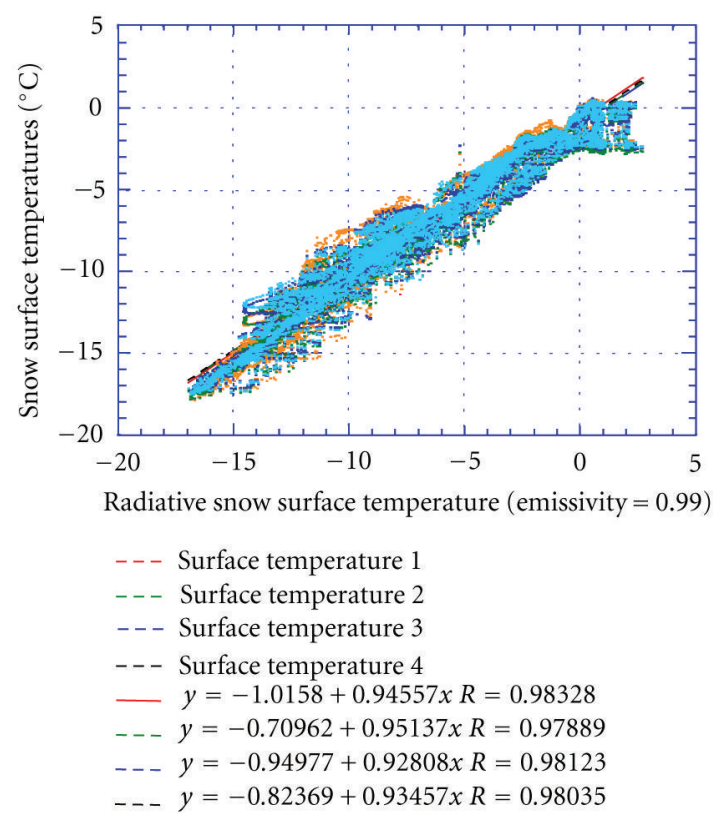

FIGURE 8: Scatter plot of surface temperature estimated from infrared radiation and the four temperature probes at $1.5 \mathrm{~cm}$ below the snow surface for a 0.99 surface emissivity.

parameterizations from the SHEBA experiment data. SHEBA parameterizations can be found in Andreas et al. $[12,16]$.

Other parameterizations, following, for example, Beljaars and Holtslag [17], De Bruin et al. [18], have also been used for stable cases.

However, as these parameterizations have been found during different atmospheric contexts and regions, we propose to test these different parameterizations and to analyze the flux range as limits in the flux estimates. It can be noticed that uncertainty on estimated bulk flux is more related to parameterization uncertainty than to the accuracy on mean variable estimates. If parameterizations were indeed really universal, they would be more precise than direct eddy flux measurement (Weill [19]).

The first step to estimate bulk flux at the surface (snow or ice) is to check that the measurement height $h$ relatively to the surface is in the surface layer where fluxes are supposed not to differ by more than $10 \%$. In the OPTIMISM project, the knowledge of $h$ is supposed to be provided by the Ice-T buoy with an uncertainty between $5 \mathrm{~cm}$ to $10 \mathrm{~cm}$.

All the parameterizations assume that Monin-Obukhov similarity (M.O.) can be applied (see Businger et al. [20]). The behaviour of these Monin-Obukhov functions is largely described in the literature, see, for example, Busch [21]. They can be expressed as follows:

$$
\begin{gathered}
u=\frac{u_{*}}{k\left[\ln \left(h / z_{0}\right)-\psi(h / L)\right]}, \\
T=T_{s}-\left(\frac{H}{\left(k \rho C_{p} u_{*}\right)}\right)\left[\ln \left(\frac{z}{z_{0 t}}\right)-\psi t\left(\frac{h}{L}\right)\right], \\
q=q_{s}-\left(\frac{E}{\left(k \rho L_{f} u_{*}\right)}\right)\left[\ln \left(\frac{z}{z_{0 q}}\right)-\psi_{q}\left(\frac{h}{L}\right)\right],
\end{gathered}
$$

where $k$ is the Von Karman constant, $z_{0}$ the roughness length, $L$ the Monin-Obukhov length, $\rho$ the air density, $C_{p}$ the specific heat for air at constant pressure, $L_{v}$ is the latent heat of vaporization of water, $T$ the air potential temperature at the level $h$ from the surface, $T_{s}$ the surface temperature, $q$ the specific humidity at $h, q_{s}$ the specific humidity at saturation, $u$ the mean wind speed, $u_{*}$ the friction velocity, $\psi$ is the "universal" function for wind speed, $\psi_{t}$ the "universal" function for temperature, $\psi_{q}$ the "universal" function for specific humidity, and $z_{0 t}$ is the roughness length for temperature, $z_{0 q}$ the roughness length for humidity.

The functions for wind, temperature, and humidity, respectively, are said as "universal," but some differences between authors are observed.

The roughness length $z_{0}$ is the level where the mean wind speed $U$ vanishes close to the surface. Many authors suppose that, at the level $z_{0}$, the values of $z_{0 t}=z_{0 q}=z_{0}$. Andreas [22], Andreas et al. [23] propose physical parameterizations of these different roughness lengths. In the case where meteorological profiles are obtained at several levels, it is indeed possible to estimate these different roughness lengths, following Panofsky and Dutton [24]. However, the bulk method used in this paper is a flux estimation using but one level in the atmosphere and one level at the surface, so we need to know a priori roughness lengths.

Bulk flux is then derived from (4) to (5) and can be written as

$$
u_{*}^{2}=C_{d} u^{2},
$$

where $C_{d}$ is the transfer coefficient for wind (to be parameterized). In the neutral case when $h / L=0$ and the universal 
functions cancel, $C_{d}$ reduces to $C d n=k^{2} / \ln \left(z / z_{0}\right)^{2}$ using (4).

In the same way are computed

$$
\begin{gathered}
H=C_{T}\left(T_{s}-T\right) u, \\
E=C_{q}\left(q_{s}-q\right) u,
\end{gathered}
$$

where $C_{T}$ and $C_{q}$ are the transfer coefficient for temperature and humidity.

Classical bulk methods generally include iterations on the unknown parameter $h / L$ as done by Bourras et al. [25], Fairall et al. [26], and Grachev et al. [14, 15]. However, to limit the number of iterations, following Grachev and Fairall [27], a bulk Richardson number directly measured from the level of measurement $h$ and surface measurements can be chosen. Recent flux parameterizations upon ice have been tested by Brunke et al. [28] and have been validated by comparing with experimental estimations by [23]. These analyses provide a very good framework to evaluate the consistency of flux derived from the bulk method, and, furthermore, these parameterizations can be used for the determination of flux uncertainty range. It will be indeed an output of the observations, in the absence of a proper validation with turbulent methods. A parameterization proposed by Price and Dunne [29] and applied by Arck and Scherer [30], upon the melting snow warrants to be used, particularly in spring. This method is justified by Lüers and Bareiss [31], in the Svalbard region, since it can be applied to thin atmospheric surface layers which exist during spring transitions. This parameterization has been used in this study. For $T_{s}$ measurement, we have chosen to use (1) (see Section 2.2.) with a surface emissivity equal to 0.99 .

\section{Bulk Heat Fluxes and Energy Budget Estimations}

4.1. Bulk Fluxes. The experiment took place during a spring period during which the atmospheric surface layer is generally thin. It is difficult to observe this layer using data from the ISAC-CNR tower since the second level is at $4 \mathrm{~m}$ height. During the observation period, several snow falls were observed, but the surface level remains unchanged as shown by the ruler at the foot of BEAR. As radiation net fluxes are positive on average, this means a direct warming of the surface associated with the visible radiation. Moreover, camera observations of the surface show a snow surface structure corresponding to patches of icy snow and dry snow as observed on photograph of Figure 4, where ice specular reflection is apparent. We present here results using the [29, 30] bulk method from which the stability is inferred from the bulk Richardson number. The aerodynamic roughness length is taken equal to $.0001 \mathrm{~m}$.

Before analyzing bulk fluxes obtained during the experiment, we find it important to briefly discuss the flux uncertainties due to an imperfect knowledge of $h$ and $z_{0}$.

4.1.1. Flux Uncertainties Related to Reference Height and Roughness Length Relative Uncertainties. We examine the errors on the neutral transfer coefficient $C_{\mathrm{dn}}$, considering that the stability errors are a priori smaller (which does not exclude uncertainties due to $C_{\mathrm{dn}}$ parameterization):

$$
\frac{d C_{\mathrm{dn}}}{C_{\mathrm{dn}}}=\left(\left(\frac{2}{\ln \left(h / z_{0}\right)}\right)\right) \frac{\partial h}{h}+\left(\frac{2}{\left(\ln \left(h / z_{0}\right)\right)}\right) \frac{\partial z_{0}}{z_{0}} .
$$

Effect of $h$ Uncertainties. We first note that a $5 \mathrm{~cm}$ error on $h$ when $h=1.7 \mathrm{~m}$ is associated with a negligible error on $C_{\mathrm{dn}}$, in any case smaller than $2 \%$ whatever the roughness lengths between $0.01 \mathrm{~m}$ and $0.0001 \mathrm{~m}$. Consequently, if $h$ is not estimated due to a lack of snow height observation, we shall have to examine the effect of an unknown $h$ for different roughness lengths. Typically, for a $h$ close to $10 \%$, it will lead to flux uncertainties, respectively, equal to $4 \%$ for $z_{0}=$ $0.01 \mathrm{~m}, 2.5 \%$ for $z_{0}=0.001 \mathrm{~m}$, and $2 \%$ for $z_{0}=.0001 \mathrm{~m}$. A $50 \%$ error on $h$ will give obviously a $19 \%$ uncertainty on fluxes. We notice, as already said, that the OPTIMISM buoy has been conceived to compute $h$ with a maximum error of $10 \mathrm{~cm}$. This will limit flux uncertainties to a maximum uncertainty of $4 \%$ whatever the $z_{0}$ values. Using [30], we have taken the same values for $z_{0}, z_{0 t}, z_{0 q}$.

Effect of $z_{0}$ Uncertainties. If $z_{0}$ error does not exceed $26 \%$, $C_{\mathrm{dn}}$ uncertainty is no more than $10 \%$ for $z_{0}=0.01 \mathrm{~m}, 7 \%$ for $z_{0}=0.001 \mathrm{~m}$, and $5 \%$ for $z_{0}=0.0001 \mathrm{~m}$. This shows that if we want to limit $d C_{\mathrm{dn}} / C_{\mathrm{dn}}$ to $10 \%$, the $z_{0}$ knowledge must be better than $26 \%$ for $z_{0}=.01 \mathrm{~m}, 37 \%$ for $z_{0}=.001 \mathrm{~m}$, and $49 \%$ for $z_{0}=0.0001 \mathrm{~m}$. Though from the literature, $z_{0}$ values are prescribed upon snow/ice [23, 28], systematic photographs of the surface could help qualitatively in the choice of roughness length, especially in case of surface transitions.

4.1.2. Bulk Flux Calculation and Effects of the Parameterization Choice. Figure 9 illustrates the sensible and latent heat fluxes evolution during the experiment. Sensible and latent heat fluxes derived from FR and IT stations show values close to each other, but $\mathrm{G}$ fluxes are very different. This can be explained by the observed differences in the meteorological data (Section 2.2). Indeed, if we suppose that transfer coefficients are well parameterized and that meteorological variables present some differences due to specific biases or uncertainties, the meteorological variables will impact the transfer function computation and the fluxes estimations following (7), (8), and (9).

However, if one computes on average the absolute value of the ratio between $H+E$ and the net radiation $R_{n}$, this value is only a few percents $(2.2 \%$ for IT, $1.7 \%$ for G and $4.2 \%$ for FR) justifying that the net radiation during this period is the dominant surface forcing.

We consider now what kind of flux difference is associated with a different roughness length parameterization. For that purpose, we adopt roughness length from [23] which takes into account the snow surface and computes aerodynamic roughness length as a function of the friction velocity using three terms: the viscous effect close to the surface, the turbulent effect following Charnock [32], and 


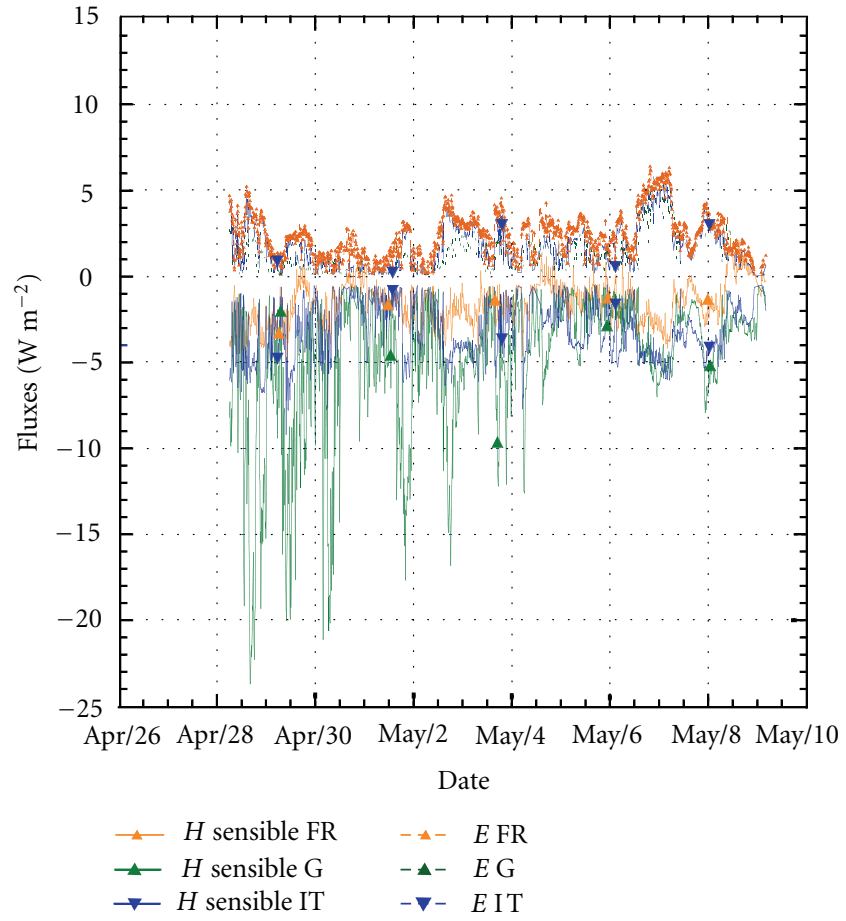

FIGURE 9: Estimates of the sensible heat flux $H$ and latent heat flux $E$, obtained from the FR, IT, and G data for the period between April 28 and May 9, 2010.

a third effect parameterizing the macroscopic structure of the surface.

We have applied this parameterization to FR, IT, and G data but effects do not depend on the sites. This parameterization on average increases latent heat flux by $24 \%$ and sensible heat flux by $31 \%$, (see Figure 10 for FR fluxes).

We also took into account effects of thermal roughness length parameterization as suggested by [23] using turbulent Reynolds number at the surface. The effect of this parameterization is to reduce sensible and latent heat fluxes of $10 \%$ on average but with a standard deviation close to $30 \%$. Thus, the discrepancies between bulk fluxes as estimated from the three stations are mainly due to differences in mean meteorological measurement from the three stations and hence only show how differences in meteorological variables propagate in the bulk fluxes. In the absence of any direct eddy flux estimate for validation and independently of meteorological possible errors, the fluxes uncertainty range due to the use of different parameterizations is important to be known. Although there is no way to judge which algorithm is the most accurate, the uncertainty range obtained by using several algorithms allows at least to help distinguishing situations where anything significant can be said about the surface budget and ice evolution. Furthermore, it is expected that the concomitant observation of the thermal field within the ice layer by the ICE-T buoy will help to discriminate the relevant fluxes values.

4.2. Energy Budget at the Surface. We now only consider here BEAR measurements, since we have already analyzed basic

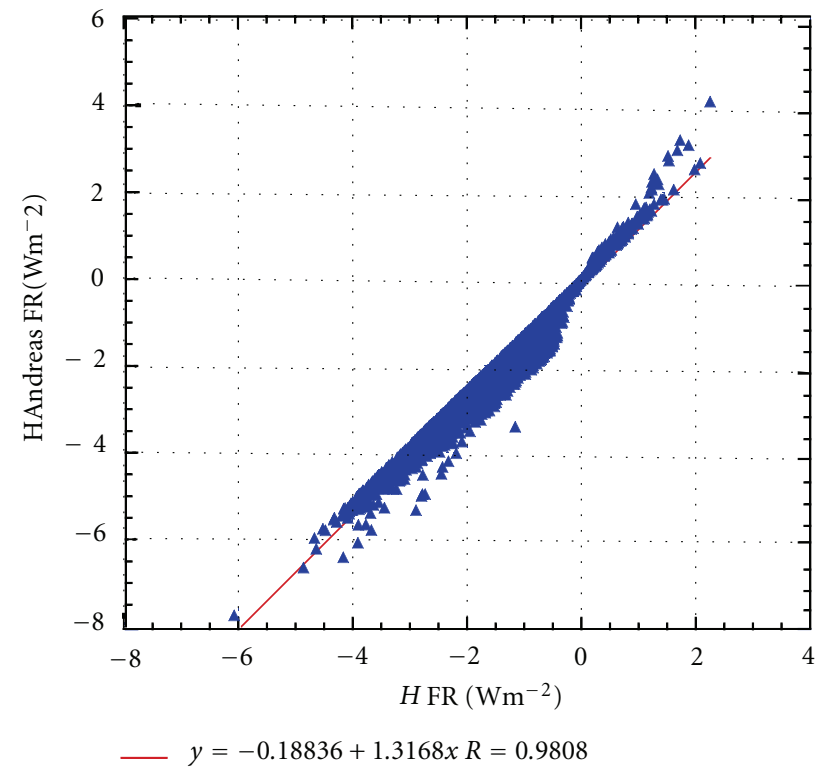

(a)

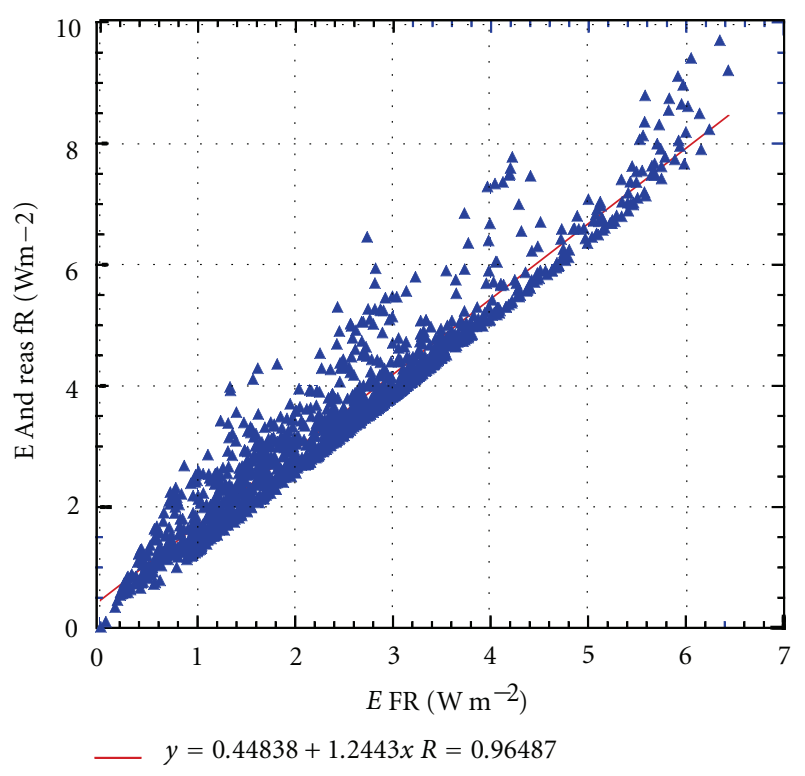

(b)

Figure 10: Comparisons between BEAR fluxes using a constant roughness length and [23] during the period between April 28 and May 29. Fluxes from [23] parameterization quoted Andreas are in vertical ordinates.

uncertainties related to the different meteorological stations in Section 2.2.

Are discussed here uncertainties which are inherent to the used methods. In the case of April-May 2010, the heat flux is indeed small which justifies that the net radiation is the most important part of the budget: see Figure 11 in which $R_{n}, H+E$, and TR are simultaneously presented as a function of time at the FR site. $H+E$ is here computed using a constant roughness length equal to $0.0001 \mathrm{~m}$, but we present also results using the parameterization from [23]. 


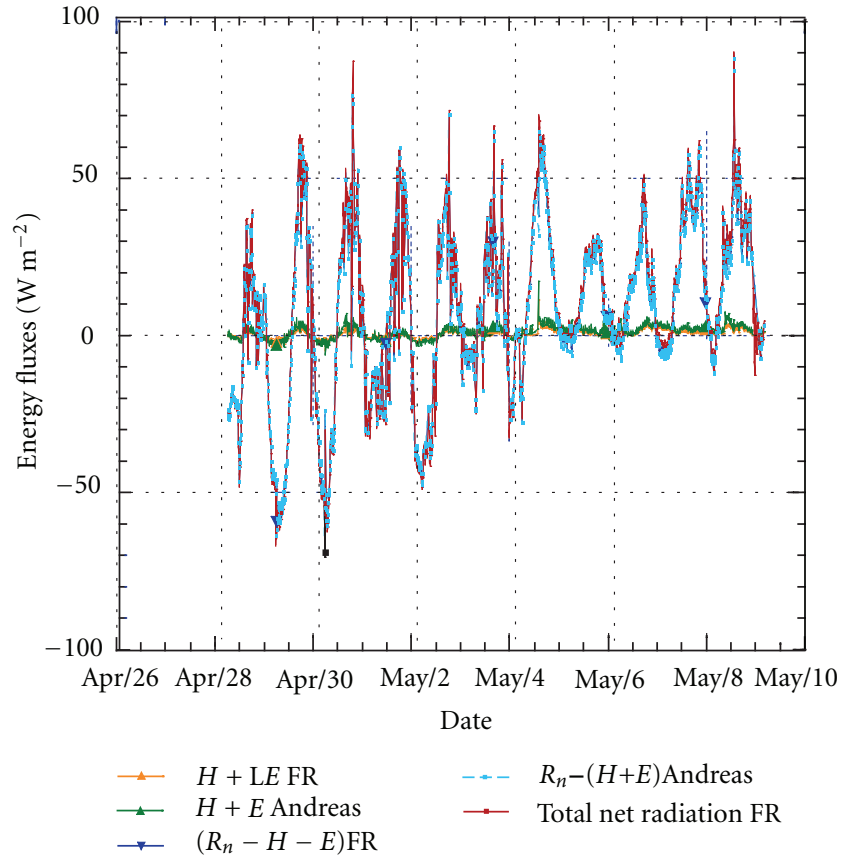

FIgURE 11: Temporal evolution of FR net radiation and turbulent bulk fluxes during the experiment. TR $=R_{n}-(H+E)$ is also represented. The different bulk fluxes and TR using $z_{0}=z_{0 t}=z_{0 q}=$ $0.0001 \mathrm{~m}$ and [23] are also on the figure and quoted Andreas.

Although $R_{n}$ is the dominant part of the energy budget during the period, at times of low radiation, the heat flux is comparable to the net radiation which leads to low values of the energy budget. Therefore, it is impossible to distinguish if TR is positive or negative at these times. This is not so important during spring transitions when net radiation presents a large diurnal cycle, but these characteristics can occur during winter when net radiation (which of course corresponds to infrared radiation at this period) is small. If such events last a long time, they can impact the energy budget which needs a better precision on bulk turbulent heat flux and would need in the future direct eddy correlation measurements for increased confidence in the energy budget estimation. During our observations, net radiation can reach a maximum value close to $50 \mathrm{Wm}^{-2}$ while the total turbulent heat flux is negative, on average small until May 4 with a typical value close to $-2 \mathrm{Wm}^{-2}$, see Figures 9 and 11 . Taking into account a $10 \%$ uncertainty on $R_{n}$ and of $40 \%$ on $H+E$ gives a relative uncertainty of $13 \%$ for a total budget of about $48 \mathrm{Wm}^{-2}$.

The 10-minute average chosen is useful to follow the evolution of atmospheric events and their variability. It will help to discriminate the relationships between atmospheric events and fluxes in relation with ice-snow Ice-T profiles.

To go a little further into the energy budget from a more integrated point of view, we have computed 24-hour average for each day of the experiment.

Figure 12 shows the daily average of the net short-wave radiation, the net long-wave radiation, the net radiation and the transmitted energy to the surface TR for the whole duration of the experiment.

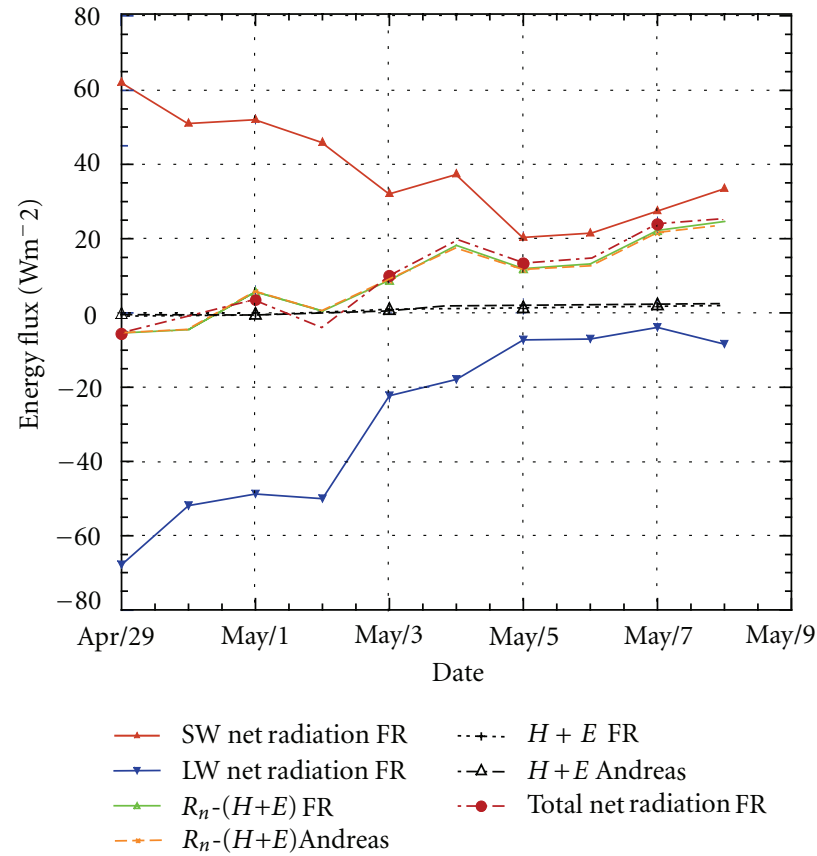

FIGURE 12: Daily averaged FR energy budget during the experiment, with each short-wave and long-wave net radiation components. TR is also drawn. The heat flux estimates are also plotted.

We notice that TR is always comparable to the net radiation and they begin to grow since May 2 . However, when $R_{n}$ or TR is small, as turbulent heat flux is always small of the same order as TR (whatever is the $z_{0}$ parameterization used), it is difficult to diagnose the sign of TR, since the uncertainty is large as previously discussed, but TR is probably zero. This is not the case as soon as $R_{n}$ becomes largely positive, since, from May 3, TR is mainly controlled by short-wave radiation which is significantly positive and associated with a direct surface warming. The mean turbulent heat flux although small constantly increases during the experiment. Although its standard deviation can reach $40 \%$ of its value, this term has little impact on TR.

If we now consider averages over the 10 days of the experiment, we notice that total net radiation reaches $10 \mathrm{Wm}^{-2}$ on average while TR is close to $9.5 \mathrm{Wm}^{-2}$ with $z_{0}=.0001 \mathrm{~m}$ and $9.2 \mathrm{Wm}^{-2}$ for Andreas parameterization. The experiment took place during a period of very low heat flux $\left(0.9 \mathrm{Wm}^{-2}\right.$ with $z_{0}=.0001 \mathrm{~m}$ and $1.2 \mathrm{Wm}^{-2}$ following [23]) with an energy budget mainly controlled by radiation fluxes.

Uncertainties on heat flux during this transition period do not seem a major issue here since $H+E$ is only $\sim 1 \%$ of TR, but these uncertainties could be a substantial problem to estimate accurate energy budget during winter when net infrared radiation becomes small particularly during cloudy situations.

\section{Conclusions}

During a short experiment in Ny Ålesund, Svalbard, BEAR station data have been successfully compared with those of 
the Italian meteorological tower and the AWI German station. This gives some confidence in the use of the BEAR meteorological and radiation data.

We have tested long-wave radiation inversion to get the surface temperature and have found that, during the conditions of the experiment, the surface emissivity of 0.99 chosen by [11] is statistically appropriate. Further investigations in Arctic regions are however warranted to see if and when this value is always appropriate.

We have tested bulk methods from [30] to estimate fluxes and have found that FR and IT sensible and latent heat fluxes were close, but with a large scatter of 30\% to $40 \%$.

Having tested parameterization from [23], we have found that although sensible and latent heat fluxes differ, by $31 \%$ and $24 \%$, respectively, the total turbulent heat fluxes do not have a large impact on the budget, since the net radiation is the most important part of the energy budget at this period.

By analyzing the daily energy, we have remarked that except for periods of low net radiation, we were able to estimate the residual energy flux transmitted to the snow/ice surface. However, as uncertainty can be large, it warrants to be analyzed jointly with the snow/ice information to be delivered by the Ice-T buoy. The low-radiation periods which can occur during winter are important and need to be more documented. The OPTIMISM buoy seems well adapted for this purpose.

Several concluding remarks and outlooks can be drawn from these analyses.

(i) In the transition period (see the schema representation in Figure 1), as the turbulent heat flux is small, our observations suggest that we are able to survey the energy budget. Estimations using independent parameterizations will help to analyze potential effects of turbulent heat fluxes, for example, in case the net radiation is strongly reduced.

(ii) Figure 1, established from [6-8], suggests that, during winter and autumn the turbulent heat flux, which generally warms the surface and is of opposite sign to the radiative flux which cools the surface, can be a large fraction of the radiation cooling. The OPTIMISM buoy can be a relevant system to document these cases.

(iii) To the question "are we able to analyze the surface energy budget and what can be the precision of estimates," we think that a $35 \%$ or more uncertainty is inherent to the bulk method. However, a simultaneous examination of the energy budget evolution and of the colocated ice thermodynamics, which is the scope of the OPTIMISM project, should at least give redundant information to determine the most probable energy budget.

(iv) The uncertainty on fluxes will make difficult to obtain the annual energy budget, which has been found to be of a few $\mathrm{Wm}^{-2}$ from SHEBA experiment [8].

Therefore, we rather suggest to explore events in the surface evolution, looking at the meteorological variables, fluxes (with their uncertainties ranges due to parameterizations), and to analyze these events impacts inside the ice-snow layer using Ice-T buoy. For that purpose, roughness lengths values impacts on radiation components and turbulent fluxes have also to be considered in relation with surface observations, because, as shown by Held et al. [33], over sea, $z_{0}$ values can vary by 2-3 orders of magnitude on quite small scales.

Another point which warrants to be examined in the future is the frost formation since it can contaminate drastically the measurements. During this campaign, the BEAR station was always operating without rime or frost due to low humidity but frost has been observed during a preliminary test in the French Alps, Loisil et al. [34]. We have not been in position to take into account and to forecast frost effects which could be a large handicap in the future. This last issue is a very difficult task but a necessary way for using the OPTIMISM buoy with BEAR in the future and the idea to have several OPTIMISM buoys in the Svalbard region and to detect a posteriori frost events to eliminate them in the dataset could mitigate this difficulty if frost does not simultaneously occur on the different buoys.

\section{Acknowledgments}

The OPTIMISM project has received support from ANR (ANR-09 BLANC 022701) and IPEV (programme 1015). It has received incitation support from LEFE (INSU/CNRS). The authors have greatly appreciated fruitful help from ISAC (CNR) and AWI (Germany) for data access during AprilMay, 2010 in Ny Ålesund. The authors also want to thank very much their reviewers for their very useful remarks which have helped to improve this paper.

\section{References}

[1] J. Sedlar, M. Tjernström, T. Mauritsen et al., "A transitioning Arctic surface energy budget: the impacts of solar zenith angle, surface albedo and cloud radiative forcing," Climate Dynamics, vol. 37, no. 7-8, pp. 1643-1660, 2010.

[2] S. Hendricks, S. Gerland, L. H. Smedsrud, C. Haas, A. A. Pfaffhuber, and F. Nilsen, "Sea-ice thickness variability in Storfjorden, Svalbard," Annals of Glaciology, vol. 52, no. 57, pp. 61-68, 2011.

[3] M. L. Timmermans, A. Proshutinsky, R. A. Krishfield et al., "Surface freshening in the Arctic Ocean's Eurasian Basin: an apparent consequence of recent change in the wind-driven circulation," Journal of Geophysical Research C, vol. 116, no. 7, Article ID C00D03, 2011.

[4] P. Rampal, J. Weiss, C. Dubois, and J.-M. Campin, "IPCC climate models do not capture Arctic sea ice drift acceleration: consequences in terms of projected sea ice thinning and decline," Journal of Geophysical Research, vol. 116, Article ID C00DO7, 17 pages, 2011.

[5] F. Vivier, 2010, http://optimism.locean-ipsl.upmc.fr/tiki-index .php.

[6] G. Maykut, "The surface heat and mass balance," in The Geophysics of Sea Ice, N. Untersteiner, Ed., Plenium, New York, NY, USA, 1986.

[7] R. G. Barry, M. C. Serreze, J. A. Maslanik, and R. H. Preller, "The Arctic sea ice-climate system: observations and modeling," Reviews of Geophysics, vol. 31, no. 4, pp. 397-422, 1993. 
[8] P. O. G. Persson, C. W. Fairall, E. L. Andreas, P. S. Guest, and D. K. Perovich, "Measurements near the Atmospheric Surface Flux Group tower at SHEBA: near-surface conditions and surface energy budget," Journal of Geophysical Research C, vol. 107, no. 10, pp. 1-35, 2002.

[9] H. Kupfer, A. Herber, and G. Köning-Langlo, "Radiation measurement and synoptic observations at Ny-Ålesund," Tech. Rep., Alfred Wegener Institute for Polar and Marine Research, 2010.

[10] K. J. Claffey, E. L. Andreas, D. K. Perovich, C. W. Fairall, P. S. Guest, and P. O. G. Persson, "Surface temperature measurement at SHEBA," in Proceedings of the 5th Conference on Polar Meteorology and Oceanography, pp. 86-90, AMS, Dallas, Tex, USA, January 1999.

[11] D. K. Perovich, T. C. Grenfell, B. Light, and P. V. Hobbs, "Seasonal evolution of the albedo of multiyear Actic sea ice," Journal of Geophysical Research C, vol. 107, no. 10, pp. 1-20, 2002.

[12] E. L. Andreas, T. W. Horst, A. A. Grachev et al., "Parametrizing turbulent exchange over summer sea ice and the marginal ice zone," Quarterly Journal of the Royal Meteorological Society, vol. 136, no. 649, pp. 927-943, 2010.

[13] C. E. Birch, I. M. Brooks, M. Tjernström et al., "The performance of a global and mesoscale model over the central Arctic Ocean during late summer," Journal of Geophysical Research D, vol. 114, no. 13, Article ID D13104, 2009.

[14] A. A. Grachev, C. W. Fairall, P. O. G. Persson, E. L. Andreas, and P. S. Guest, "Stable boundary-layer scaling regimes: the SHEBA data," Boundary-Layer Meteorology, vol. 116, no. 2, pp. 201-235, 2005.

[15] A. A. Grachev, E. L. Andreas, C. W. Fairall, P. S. Guest, and P. O. G. Persson, "SHEBA flux-profile relationships in the stable atmospheric boundary layer," Boundary-Layer Meteorology, vol. 124, no. 3, pp. 315-333, 2007.

[16] E. L. Andreas, P. O. G. Persson, R. E. Jordan et al., "Parameterizing turbulent exchange over sea ice in Winter," Journal of Hydrometeorology, vol. 11, no. 1, pp. 87-104, 2010.

[17] A. C. M. Beljaars and A. A. M. Holtslag, "Flux parameterization over land surfaces for atmospheric models," Journal of Applied Meteorology, vol. 30, no. 3, pp. 327-341, 1991.

[18] H. A. R. De Bruin, R. J. Ronda, and B. J. H. Van De Wiel, "Approximate solutions for the Obukhov length and the surface fluxes in terms of Bulk Richardson numbers," BoundaryLayer Meteorology, vol. 95, no. 1, pp. 145-157, 2000.

[19] A. Weill, "Indirect measurement of fluxes using Doppler sodar," in Land Surface Evaporation (Measurement and Parameterization), T. Schmugge and J. C. André, Eds., pp. 301-311, Springer, New York, NY, USA, 1991.

[20] J. A. Businger, J. C. Wyngaard, Y. Izumi, and E. F. Bradley, "Flux-profile relationships in the atmospheric surface layer," Journal of the Atmospheric Sciences, vol. 28, no. 2, pp. 181-189, 1971.

[21] N. E. Busch, "On the mechanics of atmospheric turbulence," in Workshop in Micrometeorology, D. A. Haugen, Ed., pp. 1-65, American Mathematical Society, 1973.

[22] E. L. Andreas, "Parameterizing scalar transfer over snow and sea ice: a review," Journal of Hydrometeorology, vol. 3, no. 4, pp. 417-432, 2002.

[23] E. L. Andreas, R. E. Jordan, and A. P. Makshtas, "Parameterizing turbulent exchange over Sea Ice: the Ice Station Weddell results," Boundary-Layer Meteorology, vol. 114, no. 2, pp. 439460, 2005.
[24] H. A. Panofsky and J. A. Dutton, Atmospheric Turbulence, Models and Methods for Engineering Applications, Wiley-Interscience, New York, NY, USA, 1984.

[25] D. Bourras, A. Weill, G. Caniaux et al., "Turbulent air-sea fluxes in the Gulf of Guinea during the AMMA experiment," Journal of Geophysical Research C, vol. 114, no. 4, Article ID C04014, 2009.

[26] C. W. Fairall, E. F. Bradley, J. E. Hare, A. A. Grachev, and J. B. Edson, "Bulk parameterization of air-sea fluxes: updates and verification for the COARE algorithm," Journal of Climate, vol. 16, no. 4, pp. 571-591, 2003.

[27] A. A. Grachev and C. W. Fairall, "Dependence of the MoninObukhov stability parameter on the Bulk Richardson number over the ocean," Journal of Applied Meteorology, vol. 36, no. 4, pp. 406-414, 1997.

[28] M. A. Brunke, M. Zhou, X. Zeng, and E. L. Andreas, "An intercomparison of bulk aerodynamic algorithms used over sea ice with data from the Surface Heat Budget for the Arctic Ocean (SHEBA) experiment," Journal of Geophysical Research C, vol. 111, no. 9, Article ID C09001, 2006.

[29] A. G. Price and T. Dunne, "Energy balance computations of snowmelt in a subarctic area," Water Resources Research, vol. 12, no. 4, pp. 686-694, 1976.

[30] M. Arck and D. Scherer, "Problems in the determination of sensible heat flux over snow," Geografiska Annaler A, vol. 84, no. 3-4, pp. 157-169, 2002.

[31] J. Lüers and J. Bareiss, "The effect of misleading surface temperature estimations on the sensible heat fluxes at a high Arctic site-the arctic turbulence experiment 2006 on Svalbard (ARCTEX-2006)," Atmospheric Chemistry and Physics, vol. 10, no. 1, pp. 157-168, 2010.

[32] H. Charnock, "Wind stress on a water surface," Quarterly Journal of the Royal Meteorological Society, vol. 81, no. 350, pp. 693-640, 1955.

[33] A. Held, I. M. Brooks, C. Leck, and M. Tjernström, "On the potential contribution of open lead particle emissions to the central Arctic aerosol concentration," Atmospheric Chemistry and Physics, vol. 11, no. 7, pp. 3093-3105, 2011.

[34] R. Loisil, L. Eymard, N. Amarouche et al., "BEAR, une station de mesure pour l'océan Arctique," La Météorologie, no. 74, 12 pages, 2011. 

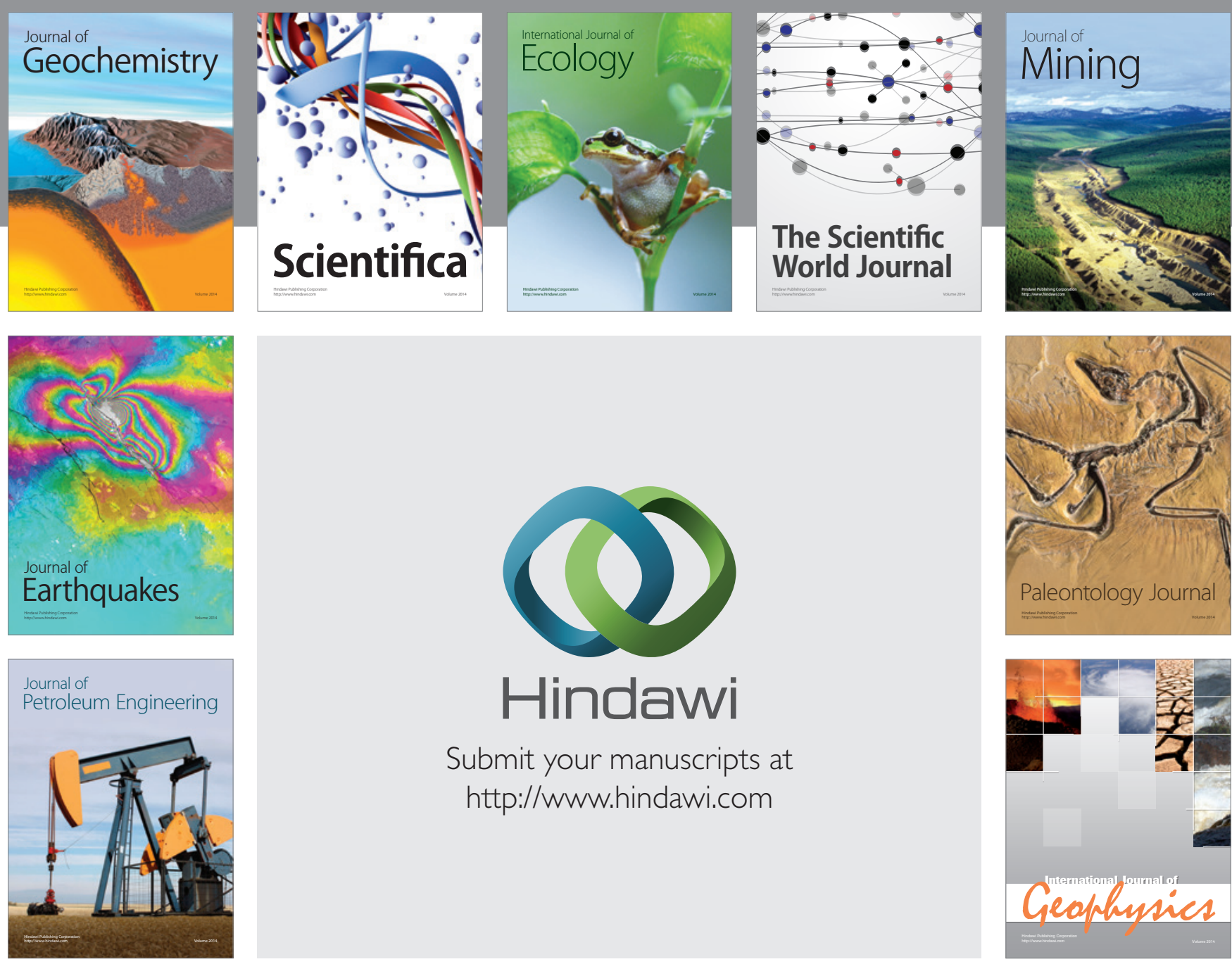

Submit your manuscripts at

http://www.hindawi.com
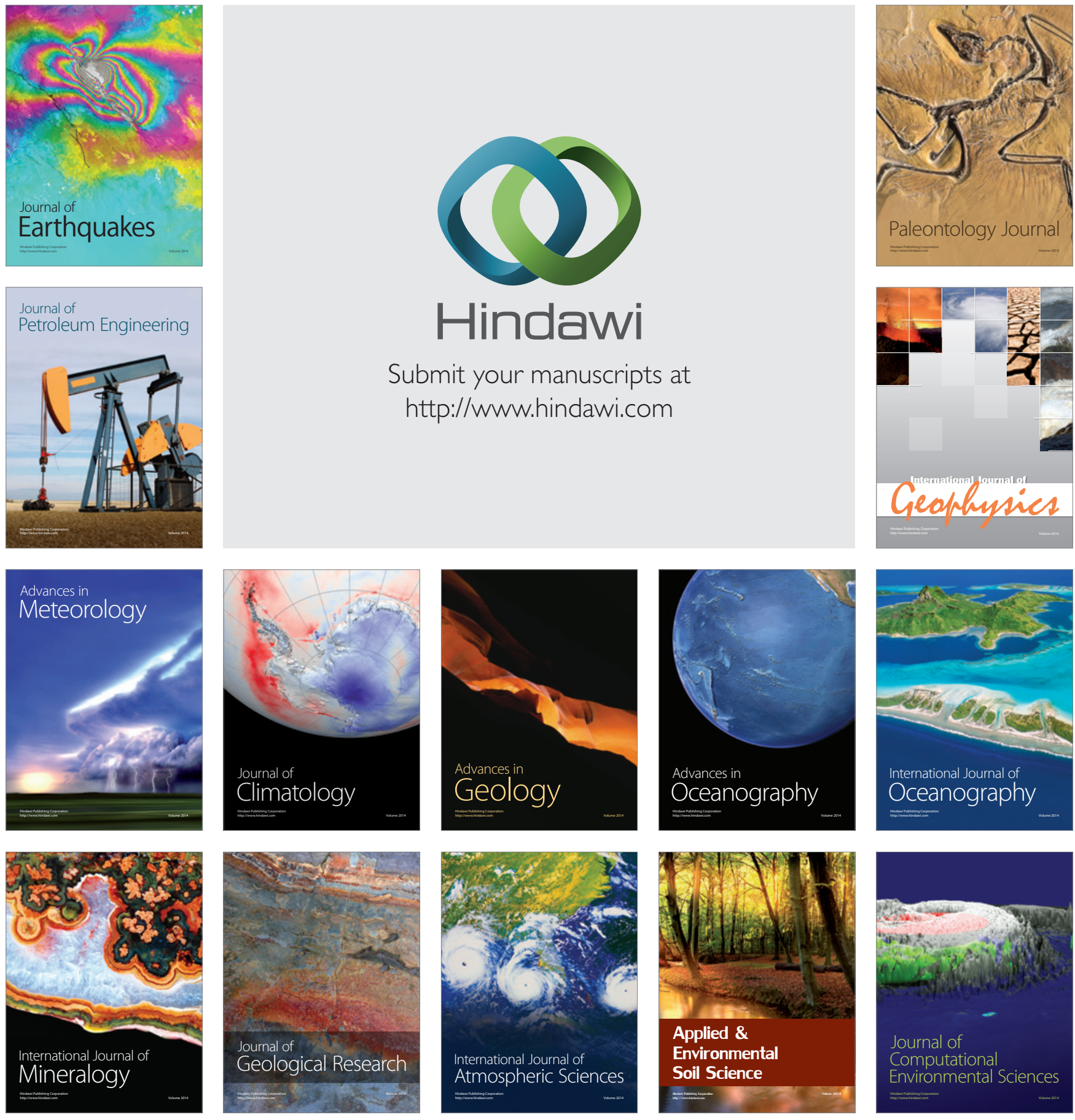